\title{
The effect of local injection of tranexamic acid into peri-articular tissue versus drain clamping in total knee arthroplasty: a randomized controlled trial
}

Ryosuke Hishimura ${ }^{1}$, Tomohiro Onodera ${ }^{1 *}\left(\mathbb{0}\right.$, Yasumitsu Ohkoshi ${ }^{2}$, Kazufumi Okada $^{3}$, Masatake Matsuoka ${ }^{1}$, Shinji Matsubara', Koji Iwasaki ${ }^{4}$, Eiji Kondo ${ }^{5}$ and Norimasa Iwasaki ${ }^{1}$

\begin{abstract}
Background: Tranexamic acid (TXA) is used as a synthetic anti-fibrinolytic agent for total knee arthroplasty (TKA) to reduce postoperative bleeding. Though the effects on bleeding reduction of several methods of administering TXA have been demonstrated, the optimal method remains controversial. Recently, the hemostatic effect of periarticular local injection of TXA during TKA was reported. Although this method can be expected to suppress postoperative bleeding without placing a drain, its hemostatic effect has not yet been assessed in comparison with local injection and other methods of administering TXA. The aim of this randomized, prospective study was to assess the efficacy of local injection of TXA during TKA.
\end{abstract}

Methods: To confirm the effect of the local injection of TXA, drain clamping was set as the control. The subjects included a prospective series of 109 patients randomly divided into 2 groups: the local injection (group L) and the drain clamping (group D). The main outcome measure was postoperative bleeding. Secondary outcomes included pain, physical measurements, and laboratory findings.

Results: The calculated total blood loss (CTBL) in groups $L$ and $D$ was nearly equal and did not show the non-inferiority of group L to group D $(883 \pm 248 \mathrm{vs} .841 \pm 257 \mathrm{ml}, P=.564)$. Drained blood loss was significantly higher in group $L$ than in group $D(395 \pm 130 \mathrm{vs} 276 \pm 78.8 \mathrm{ml}, P<.0001)$. There was no significant difference in hidden blood loss between the groups ( $488 \pm 269 \mathrm{vs} 565 \pm 261 \mathrm{ml}, P=.131)$. The other laboratory findings and physical measurements were identical between the groups.

Conclusions: Although CTBL in group L did not show non-inferiority to group D, the local injection of TXA was considered to be superior for suppressing bleeding considering the risk of the adverse effects of using a drain.

Trial registration: This was a randomized, prospective study registered with UMIN Clinical Trials Registry (Registration number: UMIN000036146, date of disclosure: 10/3/2019).

Keywords: Tranexamic acid (TXA), Periarticular local injection, Total knee arthroplasty (TKA), Drain clamping

*Correspondence: tomozou@med.hokudai.ac.jp

${ }^{1}$ Department of Orthopaedic Surgery, Faculty of Medicine and Graduate

School of Medicine, Hokkaido University, North 15 West 7, Kita-Ku, Sapporo 060-8638, Japan

Full list of author information is available at the end of the article

\section{Background}

Total knee arthroplasty (TKA) is a common surgical procedure that improves activities of daily living in osteoarthritis and rheumatoid arthritis patients, but the clinical results, including postoperative satisfaction, are original author(s) and the source, provide a link to the Creative Commons licence, and indicate if changes were made. The images or other third party material in this article are included in the article's Creative Commons licence, unless indicated otherwise in a credit line to the material. If material is not included in the article's Creative Commons licence and your intended use is not permitted by statutory regulation or exceeds the permitted use, you will need to obtain permission directly from the copyright holder. To view a copy of this licence, visit http://creativecommons.org/licenses/by/4.0/. The Creative Commons Public Domain Dedication waiver (http://creativeco mmons.org/publicdomain/zero/1.0/) applies to the data made available in this article, unless otherwise stated in a credit line to the data. 
still insufficient $[1,2]$. One of the reasons is postoperative bleeding resulting in pain and restriction of range of motion due to joint fibrosis. Although various hemostatic methods such as use of fibrin sealant [3], cryotherapy [4-6], and tranexamic acid (TXA) [7, 8] have been used to suppress postoperative bleeding after TKA, the most suitable method has not been established.

Administration of TXA is one of the most frequent techniques to prevent bleeding after TKA, and there are several administration routes [7, 9-13]. The systemic administration of TXA by the oral or intravenous route is the most commonly used, and it can significantly reduce blood loss, but it may also be associated with systemic adverse effects, such as nausea, intraoperative hypotension, and venous thromboembolism (VTE) $[14,15]$. The other is topical administration, such as drain clamping and intra-articular injection [16-19]. Drain clamping was used as a common method of reducing postoperative bleeding whereby TXA was injected through a drain tube after wound closure, and the tube was then clamped for a few hours [16-18]. Seo et al. reported that the topical administration of TXA minimized systemic complications compared to intravenous administration [20]. The combination of topical administration of TXA and drain clamping is one of the local TXA administration methods. According to the previous studies, the incidence of VTE was almost identical between drain clamping alone and the combination method $[17,18]$. This combination therapy could also be expected to show a superior effect on bleeding reduction compared to single administration [19], but there have also been some concerns about disadvantages associated with this method. The American Academy of Orthopaedic Surgeons (AAOS) 2015 clinical practice guideline recommends not using a drain with TKA because of no difference in complications or outcomes [21]. Moreover, the potential risk of retrograde infection has been pointed out [22, 23]. A safe and effective alternative to drain clamping is needed as a hemostatic method.

Local injection of TXA is often used to reduce bleeding in acute trauma surgery [24, 25]. Previous studies suggested that local injection of TXA had a suppressive effect on intra-articular hemorrhage by using a drain [17, 22 . Recently, Yozawa et al. retrospectively confirmed an effect on intra-articular bleeding reduction, which was assessed using a drain, by periarticular injection of TXA during TKA [26]. This method can be expected to suppress postoperative bleeding without placing a drain. Local administration of TXA theoretically reduces systemic adverse effects and avoids the risk of complications due to using a drain. However, whether local TXA is superior to conventional procedures remains controversial. Therefore, we hypothesized that local injection of
TXA is non-inferior to drain clamping for reducing postoperative bleeding in TKA. The aim of the present study was to prospectively compare the efficacy of periarticular local injection of TXA without drain clamping to that of injection into the knee joint through a drain combined with drain clamping during TKA.

\section{Methods}

The trial was designed according to the CONSORT guideline. This was a randomized, prospective study registered with the UMIN Clinical Trials Registry (Registration number: UMIN000036146, date of disclosure: 10/3/2019). The protocol of this study was approved by the Hakodate Orthopedic Clinic Institutional Review Board (HOC-2018-C1, 23/7/2018), and the study was performed in accordance with the tenets of the Declaration of Helsinki. The subjects provided their written, informed consent for participation in the study. All methods were carried out in accordance with relevant guidelines and regulations. This research did not receive any specific grant from funding agencies in the public, commercial, or not-for-profit sectors. A total of 120 consecutive patients were scheduled for primary unilateral TKA in Hakodate Orthopedic Clinic. The recruitment start date for the study was September 18, 2018, and the recruitment end date was July 31,2019 . The study was conducted between October 1, 2018 and August 30, 2019. The inclusion and exclusion criteria are detailed in Table 1. Exclusion criteria included the patient underwent extensive synovectomy during surgery due to severe synovitis, use of allogenic blood transfusion postoperatively, and a patient whose drain appeared to be clogged, that is, postoperative volume of drained blood less than $100 \mathrm{ml}$. In addition, it was decided to stop the study if intraoperative surgical and medical complications, such as intraoperative fracture, neurovascular injury, or myocardial infarction occurred. All eligible patients were randomized into two groups by a clerk who was not involved in medical treatment on the operation day. Randomization into two equal groups was performed with the lottery method just prior to surgery. The operating staff were blinded to the patient assignment until just before implantation during the TKA procedure. TXA was given at $10 \mathrm{mg} / \mathrm{kg}$ of body weight. In the local injection group (group L), $25 \mathrm{ml}$ of normal saline containing the above amount of TXA were injected into the area around the incision site, specifically vastus medialis and lateralis, the anterior and posterior capsule, the peripheral part of the resected meniscus, and the synovium. To clarify the role of the local injection in postoperative intraarticular bleeding, drain suction was used in accordance with the previously reported method [26]. Drain suction was started immediately after skin closure. In the drain 
Table 1 Inclusion and Exclusion Criteria

\begin{tabular}{ll}
\hline Inclusion Criteria & Exclusion Criteria \\
\hline Adult over 20years of age & Sever renal disfunction \\
Willing and able to give consent & Past history of thrombosis \\
& Extensive synovectomy during surgery \\
& Use of the allogenic blood transfusion \\
& Use of another prothesis due to procedural change \\
& Patients whose drain was clogged \\
& Patients who can not prepare the autologous blood
\end{tabular}

clamping group (group D), $30 \mathrm{ml}$ of normal saline containing the same amount of TXA were injected after skin closure through a drain. This drainage tube was clamped and closed completely for $120 \mathrm{~min}$, then released.

\section{Surgical technique and perioperative care}

All surgical procedures were performed by one surgeon (Y.O.). Under general anesthesia, the air tourniquet was inflated to $280 \mathrm{mmHg}$ during surgery. A midline skin incision was performed with a medial parapatellar approach in all patients. The prosthesis was the posterior-stabilized Persona knee implant system (Zimmer Biomet, Warsaw, IN, USA) in all cases. The bone cementing technique was similar in all cases. No local analgesic cocktail or antiinflammatory drugs were given in order to elucidate the pharmacological effects of TXA other than hemostasis. A surgical drain was placed into the knee joint. The timing for starting drain suction was different for the two groups, as mentioned above. In both groups, the drains were removed $24 \mathrm{~h}$ after surgery. An autologous blood transfusion, which was prepared preoperatively, was performed within $24 \mathrm{~h}$ postoperatively.

\section{Outcome measures}

The calculated total blood loss (CTBL) was taken as the primary outcome measure. The CTBL was calculated using a specific formula $[27,28]$ as the difference between the preoperative and postoperative day (POD) 3 hemoglobin $(\mathrm{Hb})$ level. Secondary outcome measures were as follows. The evaluated blood tests were the volume of drained blood loss (DBL) at postoperative 24h, hidden blood loss (HBL) on POD 3, and the D-dimer level on POD 7. To evaluate postoperative knee pain, patients were asked to describe their usual knee pain using a numerical rating scale (NRS) on PODs 5 and 10. The NRS is commonly used for the assessment of pain intensity $[29,30]$, and it is an 11-point scale comprising a number from 0 through 10: 0 indicates "no pain", and 10 indicates the "worst imaginable pain". As physical measurements, the range of motion (ROM) on POD 14 and the circumference of the leg at the superior patellar border (suprapatellar girth), $10 \mathrm{~cm}$ above the border (thigh girth), and the maximum circumference of the calf (calf girth) on PODs 5 and 10 were measured. Adverse events occurring within POD 14 were also examined. HBL was calculated by subtracting DBL from CTBL, considering that there was almost no bleeding during surgery. The postoperative circumference was evaluated as a percentage based on each preoperative value. The clinical data collection from medical records was performed by an independent blinded observer.

\section{Statistical analysis}

All data are presented as means \pm standard deviation (SD). It was assumed that the CTBL could be reduced by $100 \mathrm{ml}$ in group $\mathrm{L}$ compared to group $\mathrm{D}$, and that the standard deviation of both groups was $300 \mathrm{ml}$. From a clinical point of view, the non-inferiority margin was set to $50 \mathrm{ml}$. From the above settings with a significance level of 0.025 and statistical power of $80 \%$, the sample size was calculated to be 64 patients in each group. A sample size of 72 patients in each group was therefore set under the assumption that $10 \%$ of the patients would drop out. Significant differences between two groups were assessed by Student's $t$-test or the Mann-Whitney U test, as appropriate. Statistical analyses were conducted using JMP Pro version 13.1 and SAS version 9.4 statistical software (SAS Institute, Cary, NC). Significance was accepted with a one-sided $p$-value $<0.025$ for the primary outcome measure and with a two-sided $p$-value $<0.05$ for the secondary outcome measures.

\section{Results}

A total of 120 unilateral primary TKAs were prospectively analyzed during the follow-up period. Eleven patients met the exclusion criteria, and 109 patients (57 cases in Group L and 52 cases in Group D) were included in the analysis. The desired sample size was not reached within the study period set by the Ethics Committee. As a result of power recalculation to 


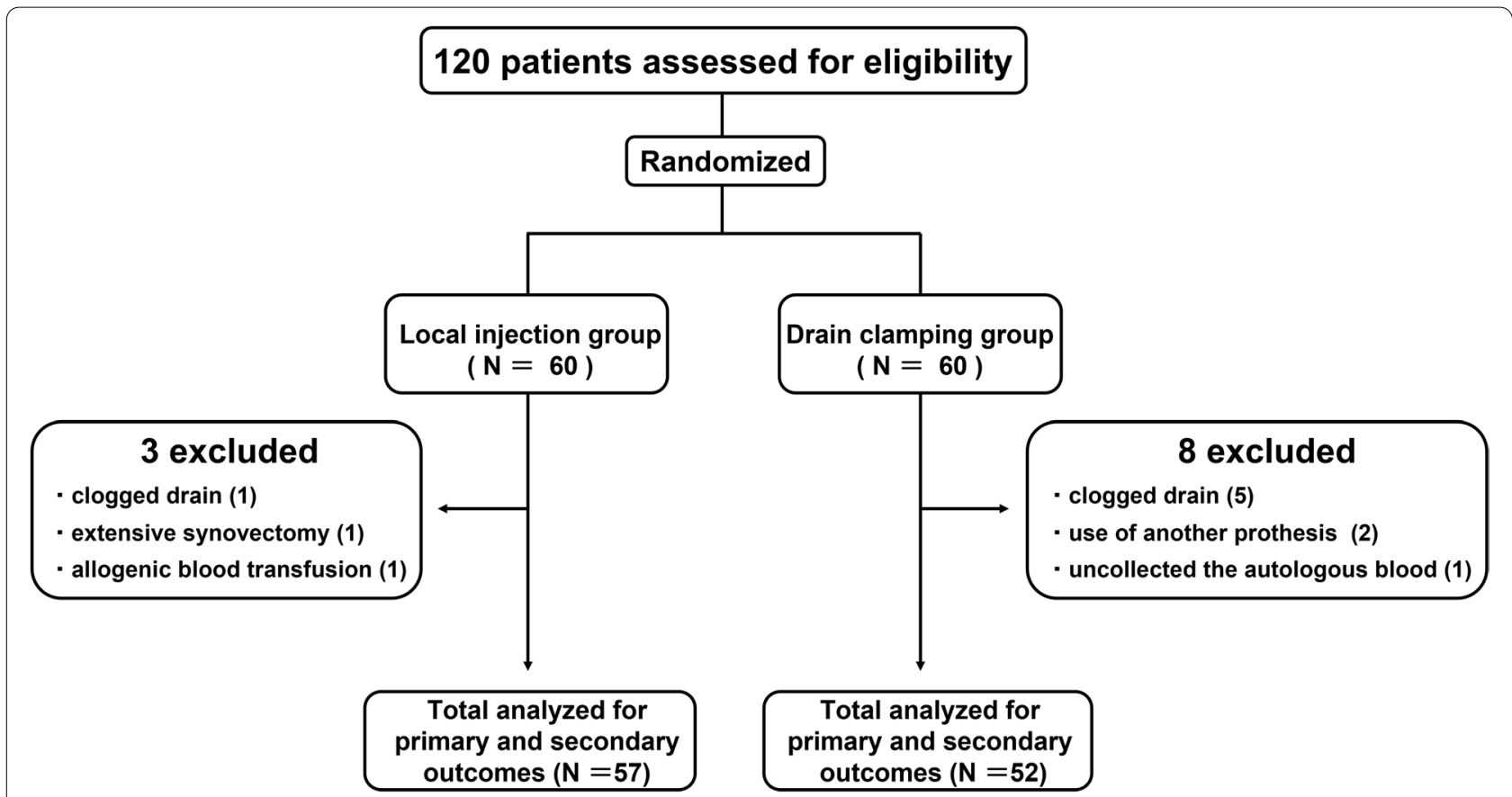

Fig. 1 Flow diagram presents the number of patients included through various stages of the study. Eleven patients met the exclusion criteria and 109 patients were included in the analysis

Table 2 Patient Demographics

\begin{tabular}{lll}
\hline Variables & Group L & Group D \\
\hline TKAs & $N=57$ & $N=52$ \\
Ages $(\mathrm{y})$ & $73.0 \pm 6.06$ & $72.6 \pm 6.07$ \\
$\mathrm{BMI}\left(\mathrm{kg} / \mathrm{m}^{2}\right)$ & $27.6 \pm 3.85$ & $28.1 \pm 3.51$ \\
Sex (Female/Male) & $49 / 8$ & $48 / 4$ \\
Diagnosis (OA/others) & $54 / 3$ & $50 / 2$ \\
\hline
\end{tabular}

Values are given as the mean and the standard deviation

OA indicates osteoarthritis, BMI Body mass index

evaluate its impact, the power was $73.4 \%$ with the included sample size. The details of the patients were as follows (Fig. 1): patients whose drain was clogged ( 6 cases; 1 case in group $\mathrm{L}$ and 5 cases in group D); patients for whom autologous blood was not prepared (1 case in group D); patients who underwent extensive synovectomy (1 case in group L); use of allogenic blood transfusion (1 case in group L); and use of another prosthesis (2 cases in group D).

Demographic data of the patients are shown in Table 2. There were no significant differences between the groups in baseline variables.

The outcomes are summarized in Table 3. As the primary outcome, the CTBL in groups L and D was nearly
Table 3 Postoperative clinical outcomes

\begin{tabular}{llll}
\hline Outcomes & Group L & Group D & $P$ value \\
\hline CTBL $(\mathrm{ml})$ & $883 \pm 248$ & $841 \pm 257$ & 0.564 \\
DBL $(\mathrm{ml})$ & $395 \pm 130$ & $276 \pm 78.8$ & $<0.0001$ \\
$\mathrm{HBL}(\mathrm{ml})$ & $488 \pm 269$ & $565 \pm 261$ & 0.1315 \\
D-dimer $(\mu \mathrm{g} / \mathrm{ml})$ & $6.50 \pm 2.80$ & $5.93 \pm 2.71$ & 0.285 \\
NRS at POD 5 & $1.96 \pm 2.45$ & $2.65 \pm 2.70$ & 0.195 \\
NRS at POD 10 & $1.81 \pm 2.32$ & $2.54 \pm 2.56$ & 0.131 \\
ROM at POD 14 & & & \\
$\quad$ Extension ( $\left.{ }^{\circ}\right)$ & $-0.93 \pm 2.32$ & $-1.59 \pm 2.92$ & 0.284 \\
$\quad$ Flexion ( ${ }^{\circ}$ ) & $106 \pm 15.1$ & $106 \pm 14.3$ & 0.886 \\
Circumference of the leg & & & \\
$\quad$ Thigh girth at POD 5 (\%) & $107 \pm 4.80$ & $107 \pm 5.25$ & 0.84 \\
$\quad$ Suprapatellar girth at POD & $109 \pm 4.74$ & $109 \pm 4.39$ & 0.556 \\
5 (\%) & & & \\
$\quad$ Calf girth at POD 5 (\%) & $102 \pm 3.96$ & $103 \pm 5.11$ & 0.575 \\
$\quad$ Thigh girth at POD 10 (\%) & $104 \pm 4.11$ & $103 \pm 4.32$ & 0.77 \\
$\quad$ Suprapatellar girth at POD & $107 \pm 5.44$ & $106 \pm 4.34$ & 0.67 \\
10 (\%) & & & \\
$\quad$ Calf girth at POD 10 (\%) & $101 \pm 4.75$ & $101 \pm 7.15$ & 0.79 \\
\hline
\end{tabular}

Values are given as the mean and the standard deviation

CTBL indicates calculated total blood loss. DBL Drained blood loss, HBL Hidden blood loss, NRS Numerical rating scale, $P O D$ Postoperative day, ROM Range of motion

Significance was accepted with a one-sided $p$-value $<0.025$ for the CTBL and with a two-sided $p$-value $<0.05$ for the secondary outcome measures 
equal and did not show the non-inferiority of group L to group D ( $883 \pm 248$ vs $841 \pm 257 \mathrm{ml}, P=.564$ for noninferiority). While there was no significant difference in HBL between the groups (group L $488 \pm 269 \mathrm{ml}$, group D $565 \pm 261 \mathrm{ml}, P=.131$ ), DBL was significantly higher in group L than in group D (group L $395 \pm 130 \mathrm{ml}$, group D $276 \pm 78.8 \mathrm{ml}, P<.0001)$. The mean $\mathrm{D}$-dimer level on POD 7 was similar in the two groups (group L $6.50 \pm 2.80 \mu \mathrm{g} / \mathrm{ml}$, group D $5.93 \pm 2.71 \mu \mathrm{g} / \mathrm{ml}, P=.285$ ). The remaining measurements in each group, NRS, ROM, and circumference of the leg, were almost identical (Table 3). No cases of adverse events within POD 14 were reported.

\section{Discussion}

The main purpose of this study was to clarify the effect on bleeding reduction of the local injection method using TXA after TKA. The CTBL in the local injection group did not show non-inferiority to that in the drain clamping group. While there was no significant difference in HBL between the groups, DBL was significantly higher in the local injection group than in the drain-clamping group.

Previous retrospective reports showed that drain clamping promoted the tamponade effect, improving intra-articular hemostasis [31, 32]. On the other hand, local injection of TXA significantly reduced the DBL and decreased hemoglobin reduction [33, 34], suggesting that local injection of TXA also had a suppressive effect on intra-articular hemorrhage. The present results showed that the intra-articular hemostatic effect of group D was superior to that of group L, which suggests that the tamponade effect of the injection into the knee joint through a drain of TXA combined with drain clamping exceeds the intra-articular hemostatic effect of the periarticular injection of TXA without drain clamping during TKA. In addition, the DBL of drain clamping with TXA was about $100 \mathrm{ml}$ less, and the standard deviation of the DBL was smaller than in a previous study [18]. This is probably because most of the diseases in this study were OA, and the bleeding risk was relatively small and constant compared to the previous study. On the other hand, clogged drains were seen in 5 group D patients and 1 group L patient. The drain may have been clogged with a hematoma caused by the drain clamping. Although the drain clamping has superior intra-articular hemostasis due to the tamponade effect, the risk of drain clogging should be taken into consideration.

Before starting this study, a non-inferiority trial was designed because we hypothesized that group $\mathrm{L}$ had an equivalent effect on bleeding reduction compared to group D. However, non-inferiority of group L compared to group D was not proven for the CTBL. This is at least partly due to the unexpectedly low blood loss in group
D. Since the drain clamping method is beneficial for the control of intra-articular hemorrhage, it is better to use it for pathological conditions in which intra-articular hemorrhage is expected to be large. Local injection may be useful for performing wide extra-articular treatment, such as dissection for a knee with contracture.

The results of other laboratory findings and of physical examination (D-dimer, NRS, ROM, and circumference of the leg) were almost identical in the two groups. There are some studies reporting the various effects of TXA other than hemostasis. Several reports indicated that topical administration of TXA does not affect postoperative range of knee motion $[20,35,36]$. The current results showed that the postoperative range of motion was similar in the two groups, which is consistent with previous reports. The animal study showed that TXA could suppress the inflammatory response [37]. Although the antiinflammatory effect of TXA, resulting in better pain relief and reduced knee swelling, was expected to be stronger with local injection than with intra-articular administration, there were no significant difference in the NRS and the circumference of the leg between the groups. Wong et al. reported that the NRS for postoperative knee pain was almost identical in the TXA and control groups [36]. The present study also showed that there was no significant difference in pain relief and knee swelling according to the method of administration.

Although many orthopedic surgeons placed closed suction drains after TKA empirically, the American Academy of Orthopedic Surgeons (AAOS) clinical practice guideline recommends not using a drain with TKA because of no difference in complications or outcomes. Similarly, randomized, controlled trials and systematic reviews demonstrated no additional benefits of using suction drainage after TKA in terms of patient outcomes [38-41]. The present results demonstrated that the drain clamping method can obtain an excellent reduction in blood loss, including superior intra-articular hemostasis. However, surgeons should pay attention to complications due to drain placement when using the drain clamping method. On the other hand, local injection of TXA has almost the same effect on bleeding reduction without drain placement. This method will be useful as a hemostatic method without the risk of complications associated with drain placement.

In recent years, other hemostatic agents have become more commonly used to control postoperative bleeding [42-45]. A systematic review and meta-analysis suggested that local administration of each hemostatic agent significantly reduced total blood loss during TKA surgery compared with placebo [45]. Systemic administration of TXA is known to carry the risk of adverse effects, including DVT [14, 15]. In the present results, local 
administration of TXA and the drain-clamping method showed an acceptable hemostatic effect without serious complications.

There were some limitations in this study. First, the assessment period of this study was 14 days after surgery. Although short-term follow-up was considered sufficient to assess the perioperative effects on bleeding reduction of the two different methods, long-term follow-up may result in different clinical outcomes. Second, since the study excluded patients who appeared to be clogged with drainage, the effectiveness of the two hemostatic methods was not fully evaluated. These patients were excluded because one of the objectives was to compare the amount of drainage blood loss (DBL) if the drain worked without clogging. Third, only symptomatic VTE and PE were counted, and D-dimer was evaluated 7 days after surgery in this study. Evaluating asymptomatic VTE and PE using ultrasonography, venography, and chest CT could provide a detailed assessment of the risk of thrombosis. Finally, drain suction was used in this study, whereas the AAOS guidelines do not recommend the use of drains in TKA. Regarding the use of drains in the perioperative period for TKA, regulations differ depending on the country and facility, and a global consensus has not yet been reached. In the present study, the use of a drain facilitated comparison of intra-articular bleeding (DBL) and extra-articular bleeding (HBL) separately between the two groups. Despite its limitations, this study is a meaningful contribution to our understanding of the hemostatic effect of local administration of TXA compared with conventional drain clamping.

\section{Conclusions}

The present results showed that the calculated blood loss in the periarticular local injection of TXA without drain clamping did not show non-inferiority to that in the injection into the knee joint through a drain of TXA combined with drain clamping during TKA. Although one cannot conclude that the local injection method could be an alternative to the drain clamp method in terms of bleeding reduction, local injection of TXA was considered to be a method that can suppress bleeding without injecting fluid into the joint after surgery without drain placement.

\section{Abbreviations}

TXA: Tranexamic acid; TKA: Total knee arthroplasty; CTBL: Calculated total blood loss; VTE: Venous thromboembolism; AAOS: The American Academy of Orthopaedic; POD: Postoperative day; DBL: Drained blood loss; HBL: Hidden blood loss; NRS: Numerical rating scale; ROM: Range of motion.

\section{Acknowledgements}

The authors are especially thankful to the physical therapists of Hakodate Orthopedic Clinic for physical assessment.

\section{Authors' contributions}

$\mathrm{RH}$ was involved in the design of the study; performed the clinical assessment, analysis, and interpretation of data; and drafted and revised the manuscript. $\mathrm{TO}, \mathrm{YO}$, and $\mathrm{KO}$ assisted with data interpretation and revised the manuscript for important intellectual content. MM, SM, KI, EK, and NI were involved in data acquisition and revised the manuscript critically for important intellectual content. All authors have read and approved the final manuscript.

\section{Funding}

We receive no specific funding from any funding bodies to carry out the work.

\section{Availability of data and materials}

The datasets used and/or analyzed during the current study are available from the corresponding author on reasonable request.

\section{Declarations}

\section{Ethics approval and consent to participate}

This was a randomized, prospective study registered with the UMIN Clinical Trials Registry (Registration number: UMIN000036146, date of disclosure: 10/3/2019). The protocol of this study was approved by the Hakodate Orthopedic Clinic Institutional Review Board (HOC-2018-C1, 23/7/2018). The informed consent was obtained from all participants on a written document.

\section{Consent for publication}

Not applicable.

\section{Competing interests}

The authors declare no conflicts of interest associated with this study.

\section{Author details}

${ }^{1}$ Department of Orthopaedic Surgery, Faculty of Medicine and Graduate School of Medicine, Hokkaido University, North 15 West 7, Kita-Ku, Sapporo 060-8638, Japan. ${ }^{2}$ Department of Orthopaedic Surgery, Hakodate Orthopedic Clinic, 2-115, Hakodate, Ishikawa 048-0802, Japan. ${ }^{3}$ Clinical Research and Medical Innovation Center, Hokkaido University Hospital, North 15 West 7, Kita-Ku, Sapporo 060-8638, Japan. ${ }^{4}$ Department of functional reconstruction for the knee joint, Hokkaido University, North 15, West 7, Kita-ku, Sapporo, Hokkaido 060-8638, Japan. ${ }^{5}$ Centre for Sports Medicine, Hokkaido University Hospital, North 15 West 7, Kita-Ku, Sapporo 060-8638, Japan.

Received: 1 August 2021 Accepted: 24 January 2022

Published online: 02 February 2022

\section{References}

1. Scott CE, Howie CR, MacDonald D, Biant LC. Predicting dissatisfaction following total knee replacement: a prospective study of 1217 patients. J Bone Joint Surg Br. 2010;92(9):1253-8.

2. Bachmeier CJM, March LM, Cross MJ, Lapsley HM, Tribe KL, Courtenay BG, et al. A comparison of outcomes in osteoarthritis patients undergoing total hip and knee replacement surgery. Osteoarthr Cartil. 2001;9(2):137-46.

3. Levy O, Martinowitz U, Oran A, Tauber C, Horoszowski H. The use of fibrin tissue adhesive to reduce blood loss and the need for blood transfusion after total knee arthroplasty. A prospective, randomized, multicenter study. J Bone Joint Surg Am. 1999;81(11):1580-8.

4. Ohkoshi Y, Ohkoshi M, Nagasaki S, Ono A, Hashimoto T, Yamane S. The effect of cryotherapy on intraarticular temperature and postoperative care after anterior cruciate ligament reconstruction. Am J Sports Med. 1999;27(3):357-62.

5. Gibbons C, Solan M, Ricketts D, Patterson M. Cryotherapy compared with Robert Jones bandage after total knee replacement: a prospective randomized trial. Int Orthop. 2001;25(4):250-2.

6. Chughtai M, Sodhi N, Jawad M, Newman JM, Khlopas A, Bhave A, et al. Cryotherapy treatment after Unicompartmental and Total knee arthroplasty: a review. J Arthroplast. 2017;32(12):3822-32.

7. Alshryda S, Sarda P, Sukeik M, Nargol A, Blenkinsopp J, Mason JM. Tranexamic acid in total knee replacement: a systematic review and meta-analysis. J Bone Joint Surg Br. 2011;93(12):1577-85. 
8. Wang D, Wang HY, Luo ZY, Meng WK, Pei FX, Li Q, et al. Blood-conserving efficacy of multiple doses of oral tranexamic acid associated with an enhanced-recovery programme in primary total knee arthroplasty: a randomized controlled trial. Bone Joint J. 2018;100-B(8):1025-32.

9. Fillingham YA, Ramkumar DB, Jevsevar DS, Yates AJ, Shores P, Mullen K, et al. The efficacy of tranexamic acid in Total knee arthroplasty: a network Meta-analysis. J Arthroplast. 2018;33(10):3090-8.e1

10. Alshryda S, Mason J, Vaghela M, Sarda P, Nargol A, Maheswaran S, et al. Topical (intra-articular) tranexamic acid reduces blood loss and transfusion rates following Total knee replacement. J Bone Joint Surg Am Vol. 2013;95(21):1961-8.

11. Fillingham YA, Ramkumar DB, Jevsevar DS, Yates AJ, Shores P, Mullen K, et al. The safety of tranexamic acid in Total joint arthroplasty: a direct Meta-analysis. J Arthroplast. 2018;33(10):3070-82.e1.

12. Huang Z, Xie X, Li L, Huang Q, Ma J, Shen B, et al. Intravenous and topical tranexamic acid alone are superior to tourniquet use for primary Total knee arthroplasty. J Bone Joint Surg. 2017;99(24):2053-61.

13. Yamada K, Imaizumi T, Uemura M, Takada N, Kim Y. Comparison between 1-hour and 24-hour drain clamping using diluted epinephrine solution after total knee arthroplasty. J Arthroplast. 2001;16(4):458-62.

14. Sundström A, Seaman $H$, Kieler $H$, Alfredsson L. The risk of venous thromboembolism associated with the use of tranexamic acid and other drugs used to treat menorrhagia: a case-control study using the general practice research database. BJOG Int J Obstet Gynaecol. 2009;116(1):91-7.

15. Taparia MCF, Laahy MF. Pulmonary embolism associated with tranexamic acid in severe acquired haemophilia. Eur J Haematol. 2002;68:307-9.

16. Tsumara N, Yoshiya S, Chin T, Shiba R, Kohso K, Doita M. A prospective comparison of clamping the drain or post-operative salvage of blood in reducing blood loss after total knee arthroplasty. J Bone Joint Surg Br. 2006;88(1):49-53.

17. Liao L, Chen Y, Tang Q, Chen Y-y, Wang W-c. Tranexamic acid plus drainclamping can reduce blood loss in total knee arthroplasty: a systematic review and meta-analysis. Int J Surg. 2018;52:334-41.

18. Onodera T, Majima T, Sawaguchi N, Kasahara Y, Ishigaki T, Minami A. Risk of deep venous thrombosis in drain clamping with tranexamic acid and Carbazochrome sodium sulfonate hydrate in Total knee arthroplasty. J Arthroplast. 2012;27(1):105-8.

19. Chareancholvanich K, Siriwattanasakul P, Narkbunnam R, Pornrattanamaneewong C. Temporary clamping of drain combined with tranexamic acid reduce blood loss after total knee arthroplasty: a prospective randomized controlled trial. BMC Musculoskelet Disord. 2012;20(13):124.

20. Seo J-G, Moon Y-W, Park S-H, Kim S-M, Ko K-R. The comparative efficacies of intra-articular and IV tranexamic acid for reducing blood loss during total knee arthroplasty. Knee Surg Sports Traumatol Arthrosc. 2012;21(8):1869-74.

21. McGrory BJ, Weber KL, Jevsevar DS, Sevarino K. Surgical Management of Osteoarthritis of the knee. J Am Acad Orthop Surg. 2016;24(8):e87-93.

22. Drinkwater CJ, Neil MJ. Optimal timing of wound drain removal following total joint arthroplasty. J Arthroplast. 1995;10(2):185-9.

23. Willemen D, Paul J, White SH, Crook DW. Closed suction drainage following knee arthroplasty. Effectiveness and risks. Clin Orthop Relat Res. 1991;1(264):232-4.

24. Drakos A, Raoulis V, Karatzios K, Doxariotis N, Kontogeorgakos V, Malizos $K$, et al. Efficacy of local Administration of Tranexamic Acid for blood salvage in patients undergoing intertrochanteric fracture surgery. J Orthop Trauma. 2016;30(8):409-14.

25. Virani SR, Dahapute AA, Panda I, Bava SS. Role of local infiltration of tranexamic acid in reducing blood loss in Peritrochanteric fracture surgery in the elderly population. Malays Orthop J. 2016;10(3):26-30.

26. Yozawa S, Ogawa H, Matsumoto K, Akiyama H. Periarticular injection of tranexamic acid reduces blood loss and the necessity for allogeneic transfusion after Total knee arthroplasty using autologous transfusion: a retrospective observational study. J Arthroplast. 2018;33(1):86-9.

27. Gross JB. Estimating allowable blood loss: corrected for dilution. Anesthesiology. 1983;58(3):277-80.

28. Nadler SB, Hidalgo $\mathrm{JH}$, Bloch T. Prediction of blood volume in normal human adults. Surgery. 1962;51(2):224-32.

29. Caraceni A, Cherny N, Fainsinger R, Kaasa S, Poulain P, Radbruch L, et al. Pain measurement tools and methods in clinical research in palliative care: recommendations of an expert working Group of the European Association of palliative care. J Pain Symptom Manag. 2002;23(3):239-55.
30. Hjermstad MJ, Fayers PM, Haugen DF, Caraceni A, Hanks GW, Loge JH, et al. Studies comparing numerical rating scales, verbal rating scales, and visual analogue scales for assessment of pain intensity in adults: a systematic literature review. J Pain Symptom Manag. 2011;41(6):1073-93.

31. Holt BT, Parks NL, Engh GA, Lawrence JM. Comparison of closed-suction drainage and no drainage after primary total knee arthroplasty. Orthopedics. 1997;20(12):1121-4 discussion 4-5.

32. Ovadia D, Luger E, Bickels J, Menachem A, Dekel S. Efficacy of closed wound drainage after total joint arthroplasty. A prospective randomized study. J Arthroplasty. 1997;12(3):317-21.

33. Mao Z, Yue B, Wang Y, Yan M, Dai K. A comparative, retrospective study of peri-articular and intra-articular injection of tranexamic acid for the management of postoperative blood loss after total knee arthroplasty. BMC Musculoskelet Disord. 2016;17(1):438.

34. Pinsornsak P, Rojanavijitkul S, Chumchuen S. Peri-articular tranexamic acid injection in total knee arthroplasty: a randomized controlled trial. BMC Musculoskelet Disord. 2016;17:313.

35. Georgiadis AG, Muh SJ, Silverton CD, Weir RM, Laker MW. A prospective double-blind placebo controlled trial of topical tranexamic acid in Total knee arthroplasty. J Arthroplast. 2013;28(8):78-82.

36. Wong J, Abrishami A, El Beheiry H, Mahomed NN, Roderick Davey J, Gandhi R, et al. Topical application of tranexamic acid reduces postoperative blood loss in Total knee arthroplasty. J Bone Joint Surg Am Vol. 2010;92(15):2503-13.

37. Busuttil SJ, Ploplis VA, Castellino FJ, Tang L, Eaton JW, Plow EF. A centra role for plasminogen in the inflammatory response to biomaterials. J Thromb Haemostasis. 2004;2(10):1798-805.

38. Wang D, Xu J, Zeng W-n, Zhou K, Xie T-h, Chen Z, et al. Closed suction drainage is not associated with faster recovery after Total knee arthroplasty. Orthop Surg. 2016;8(2):226-33.

39. Zhou K, Wang H, Li J, Wang D, Zhou Z, Pei F. Non-drainage versus drainage in tourniquet-free knee arthroplasty: a prospective trial. ANZ J Surg. 2017;87(12):1048-52.

40. Quinn M, Bowe A, Galvin R, Dawson P, O'Byrne J. The use of postoperative suction drainage in total knee arthroplasty: a systematic review. Int Orthop. 2015;39(4):653-8.

41. Zhang Q, Liu L, Sun W, Gao F, Zhang Q, Cheng L, et al. Are closed suction drains necessary for primary total knee arthroplasty? Medicine (Baltimore). 2018;97(30):e11290.

42. Helito CP, Bonadio MB, Sobrado MF, Giglio PN, Pécora JR, Camanho GL, et al. Comparison of Flosea ${ }^{\circledR}$ and tranexamic acid for bleeding control after Total knee arthroplasty: a prospective randomized study. Clinics. 2019;74:e1186

43. Echave M, Oyaguez I, Casado MA. Use of Floseal(R), a human gelatinethrombin matrix sealant, in surgery: a systematic review. BMC Surg. 2014:20(14):111.

44. Li J, Li H-B, Zhai X-C, Qin L, Jiang X-Q, Zhang Z-H. Topical use of topical fibrin sealant can reduce the need for transfusion, total blood loss and the volume of drainage in total knee and hip arthroplasty: a systematic review and meta-analysis of 1489 patients. Int J Surg. 2016;36:127-37.

45. Li S, Chen B, Hua Z, Shao Y, Yin H, Wang J. Comparative efficacy and safety of topical hemostatic agents in primary total knee arthroplasty. Medicine (Baltimore). 2021;100(12):e25087.

\section{Publisher's Note}

Springer Nature remains neutral with regard to jurisdictional claims in published maps and institutional affiliations. 